\title{
HARDNESS AND MICROSTRUCTURE OF FUNCTIONALLY GRADED ALUMINIUM SILICON ALLOY WITH MULTIWALL CARBON NANOTUBE COMPOSITE BY POWDER METALLURGY WITH HOT EXTRUSION TECHNIQUE
}

\author{
AZEEM PASHA\& B.M. RAJAPRAKASH
}

Department of Mechanical Engineering, UVCE, Bangalore University, Bangalore, Karnataka, India

\begin{abstract}
A multi-wallcarbon nanotube-reinforcedfunctionallygradedAlSi composite producedin 4-layers by powdermetallurgywith a hot extrusion technique by varying MWCNT by wt\% $(0,0.25,0.5$, and 0.75). Ball millingisemployed to mix multiwallcarbon nanotube with Aluminium siliconalloypowder for 6hours by takingsuitableparameters. Cold compaction didstrengthen 4-layer functionallygraded composite material and thenfollowed by hot extrusion. The specimencutlongitudinallyusingwirecutting machine for opticalmicroscopy to study the microstructure to evaluate multiwallcarbon nanotube distribution over the sample'slengthwithincreasing concentration. SEM morphology of powdered mixture of AlSiwith MWCNT images indicating the distribution of MWCNTs over the AlSi surface. EDX analyses carry out to confirm the constituents of matrix and reinforcement. Hardnessimproved over the length by $78 \%$ for AlSi+0.75wt\% in the FGM layer concerning the increasing concentration of multi-wallcarbon nanotube in the FGMC specimen.

KEYWORDS: Aluminium siliconalloy, Automobile, Functionallygradedmaterials, hot extrusion, Multiwallcarbon nanotubes\&Powder metallurgy
\end{abstract}

Received: Jun 08, 2020; Accepted: Jun 28, 2020; Published: Sep 12, 2020; Paper Id.: IJMPERDJUN20201174

\section{INTRODUCTION}

Lightweight and high strength capabilities, MMC's play a vital role in the Aircraft and Aerospace sector(B. Chen et al., 2016)(Luo et al., 2007; Rao SS, 2015). In MMC's Aluminium, alloys provide excellent material properties with the demand of the industry(shankar et al., 2016). Still, MMC's will fail when subjected to differences in temperature variations such as thermal stresses in Aerospace applications, delamination of chromium coating on piston ring due to difference in coefficient of thermal expansion overcome by FGM(Topolski et al., 2014)(Tang et al., 2020). Functionally graded material composites are initially invented by the Japanese to relieve the thermal stresses in aerospace structures(Salesky, 1987). Functionally graded materials are novel materials with tailoring properties over the single component by varying the constituents in a controllable manner(Z. Chen et al., 2018). The FGM phenomenon can be applied to MMCs to develop parts with varying reinforcements over the region, improving the modulus of elasticity, tensile, and compressive strength and wear resistance properties(Khorsand \& Tang, 2018).Iijima's advent of nano-size materials such as carbon nanotubes led to tremendous changes in the material science field with their excellent properties and intact structure(Maruyama et al., 2016). With outstanding properties in physical, mechanical, thermal \& electrical properties in CNTs revolutionized several Engineering sectors(Sobczak \& Drenchev, 2013)(Kim et al., 2019; Mahamood et al., 2012). FGM has been synthesized by ball milling to get uniform distribution of CNTs over the $\mathrm{Al}$ and hot pressing process(Kim et al., 2019). Functionally graded materials able to solve thermal delamination problem of chromium coating of piston rings due to difference in co-efficient of 
thermal expansion, similarly Functionally graded materials helps in relieving thermal stresses of Aerospace ships.

\section{MATERIAL \& EXPERIMENTAL METHOD}

The Aluminium siliconalloypowder and multiwallcarbon nanotubes mixed usingballmillingequipmentemployedisaplanetaryballmilling machine. The ballmillingparametersmaintained in mechanicalalloying are milling speed of 150rpm, BPR ratio of 2:1, process control agent (PCA) isethanol, and steelhardenedballs of diameter 10mm used(Al-Aqeeli, 2013). The ballmillingiscarried out for 6hours to avoid damage to multiwallcarbon nanotubes(Z. Y. Liu et al., 2012).Mixing of MWCNT to AlSipowder in wt\% of (0, 0.25, 0.5 \& 0.75). In cold compaction, the mixture of differentwt\% of AlSi\& MWCNT kept in layerswithseparateweightcalculations for eachpowder(Powell, 2013). Eachpowderisweighedusing the rule of the mix and poured in die and jolted to make the dustsettled down properly, then the load of $100 \mathrm{KN}$ isapplied to get a green compactedspecimen of dimension $20 \mathrm{~mm}$ diameter and length $25 \mathrm{~mm}$. The cold compactedsampleisplaced in a hot extrusion die kept in a mufflefurnaceat $610^{\circ} \mathrm{C}$ for 1hour and thenextrudedusing the UTM machine of capacity $600 \mathrm{KN}$ with extrusion ratio \& ram speed of $4: 1$ and $0.5 \mathrm{~mm} / \mathrm{sec}$ respectively. The sameheatused for extrusion, whichused for sintering(Lin et al., 1996).

\section{RESULTS AND DISCUSSIONS}

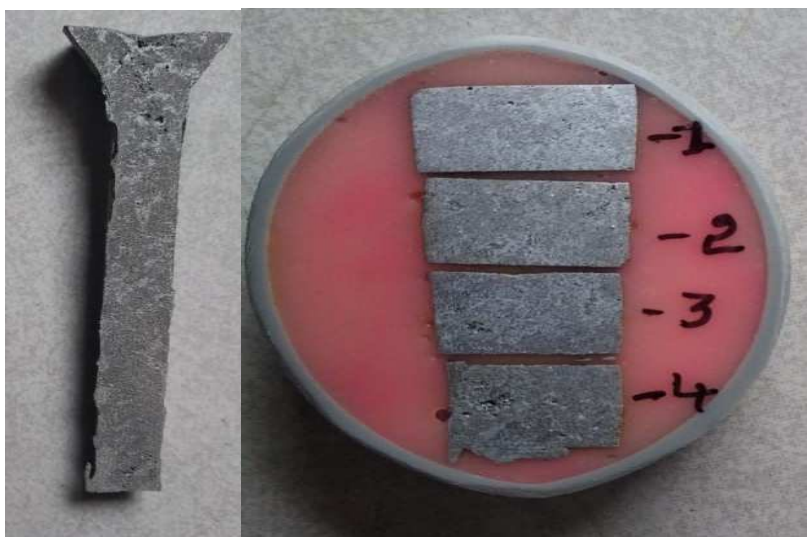

(a)

(b)

Figure 1.a) -FunctionallyGradedMaterial Composite (FGMC) with 4-layers; b)- . FGMC cutin 4-layers witheachlayer of $15 \mathrm{~mm}$

Figure.1a) depictsthatitis a 4layer FunctionallyGradedMaterialcomposite consists of

1. Bottom layer 1- AlSi+0wt\% MWCNT

2. Layer 2- AlSi+0.25wt\% MWCNT

3. Layer 3- AlSi+0.50wt\% MWCNT

4. Top layer Layer 3- AlSi+0.75wt\% MWCNT

The FGMC specimencutusingwirecutting machine, and each layer isprepared for opticalmicroscopy to evaluate the multiwallcarbon nanotubes concentration over the length of the sample(Watari et al., 1997). The specimencutin 4layers and each layer is for a range of $15 \mathrm{~mm}$ and studied for the controlledlevel of multiwallcarbon nanotubes shown in Figure .1b)

Figure. 1b)FGMCsamplepredicts 
1- $\quad$ Indicates Layer 1- AlSi+0wt\% MWCNT

2- $\quad$ Indicates Layer 2-AlSi+0.25wt\% MWCNT

3- $\quad$ Indicates Layer 3-AlSi+0.50wt\% MWCNT

4- $\quad$ Indicates Layer 4-AlSi+0.75wt\% MWCNT

The equipmentused to study the microstructure of constituents in FGMC is Nikon Microscope LV150 withClemex Image Analyser. Figure3. shows the distribution morphologies of multiwallcarbon nanotubes in Aluminium siliconalloywith the controlled variation of MWCNT in the AlSi matrix. Fig.3a), b), c) and d) show the increase in the concentration of MWCNT in the AlSi. The microstructure consists of uniformlydispersedeutecticsiliconneedles and fine precipitates of alloyingelements (MWCNT) in the aluminumsolid solution matrix. Particlesscattered in the dendriticregion(S. Liu et al., 2020)

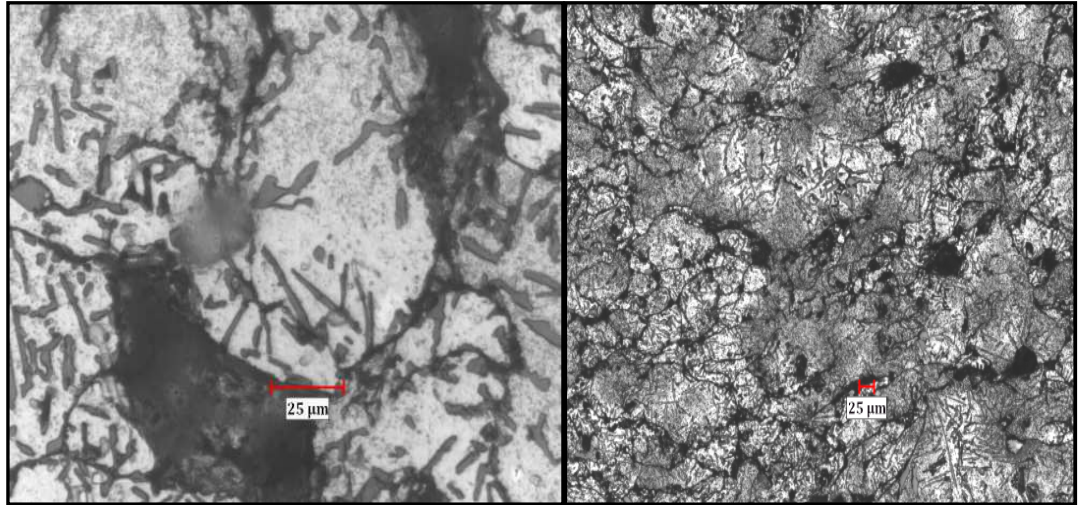

(a)

(b)

$100 \mu \mathrm{m}$

$500 \mu \mathrm{m}$

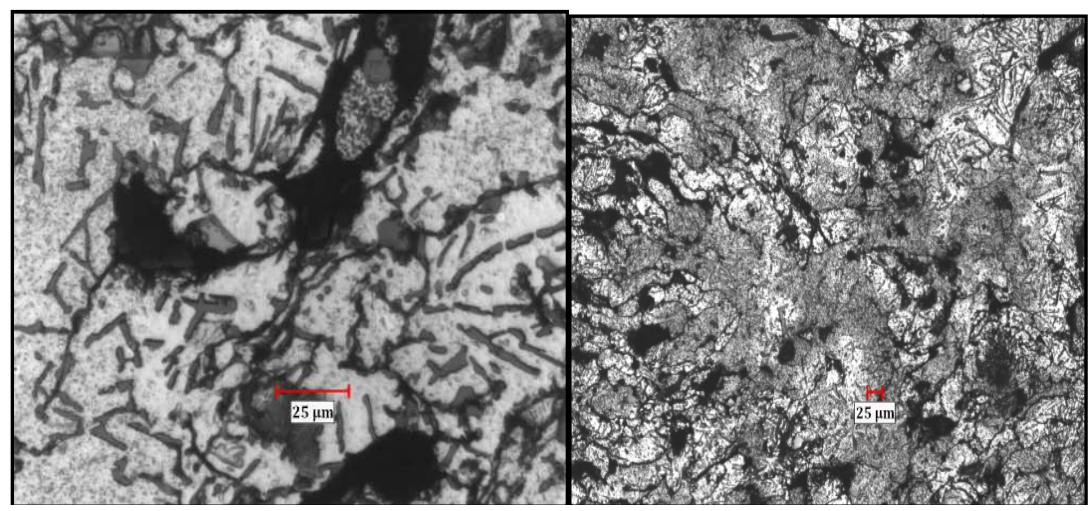

(c)

$100 \mu \mathrm{m}$

$500 \mu \mathrm{m}$ 


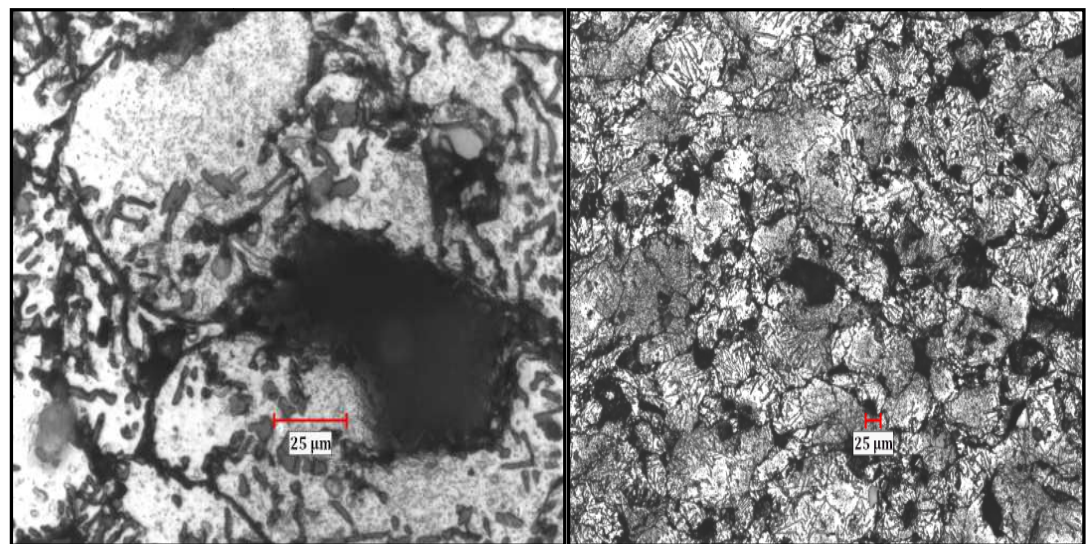

(e)

$100 \mu \mathrm{m}$

(f)

$500 \mu \mathrm{m}$

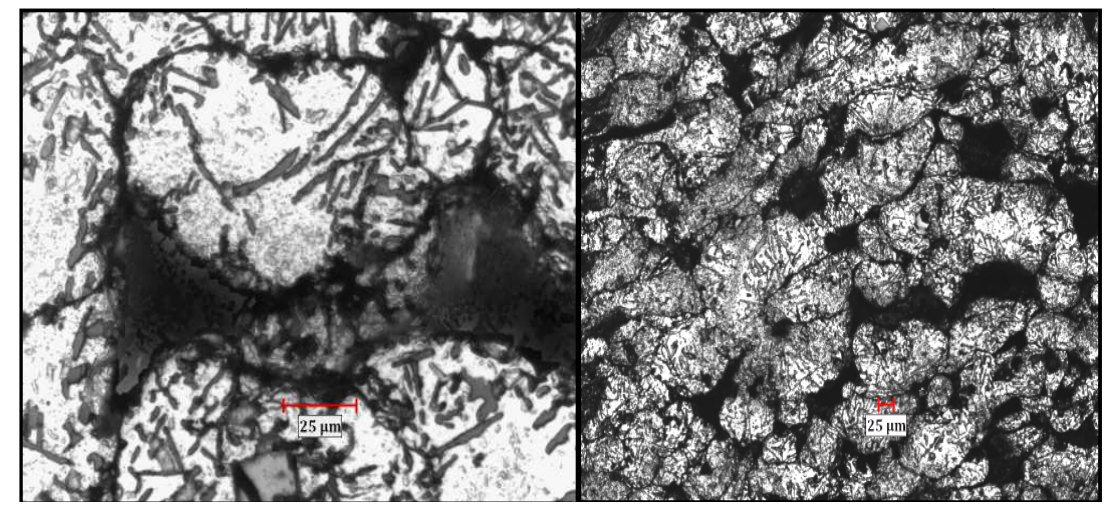

(g)

(h)

$100 \mu \mathrm{m}$

$\mathbf{5 0 0 \mu m}$

Figure 2: OM images of AlSiwith MWCNT variation, (a,b) AlSiwith 0wt\% of MWCNT, (c,d) AlSiwith 0.25 wt\% of MWCNT, (e,f) AlSiwith 0.5wt \% of MWCNT(g,h) AlSiwith 0.75wt\% of MWCNT

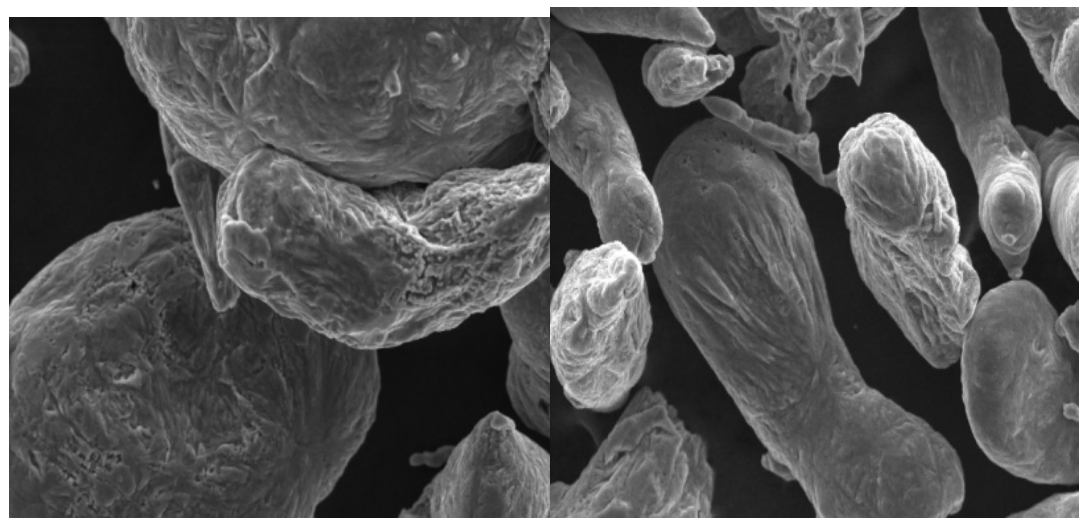

(a)

(b) 


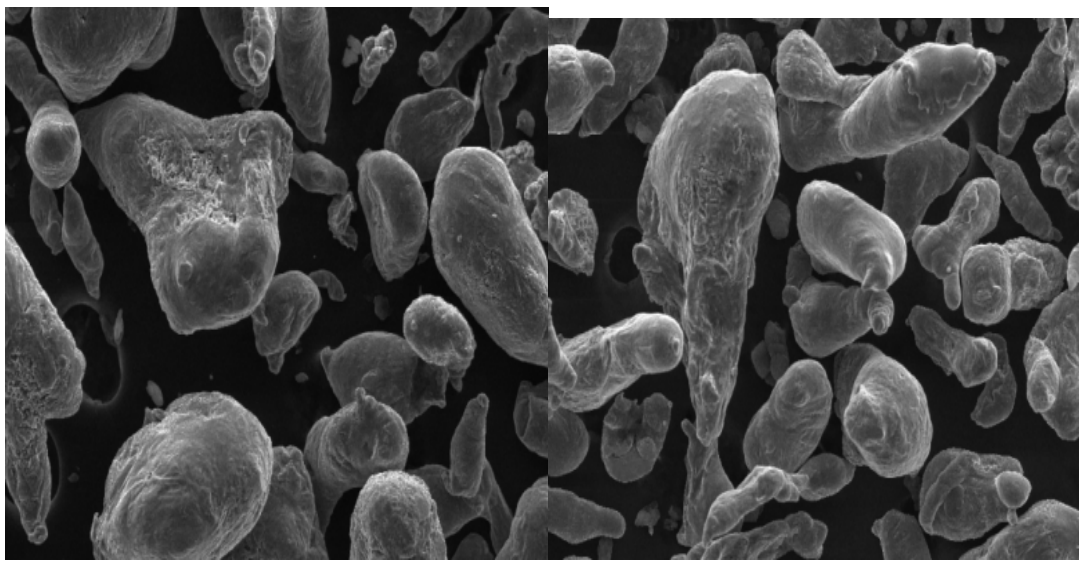

(c)

(d)

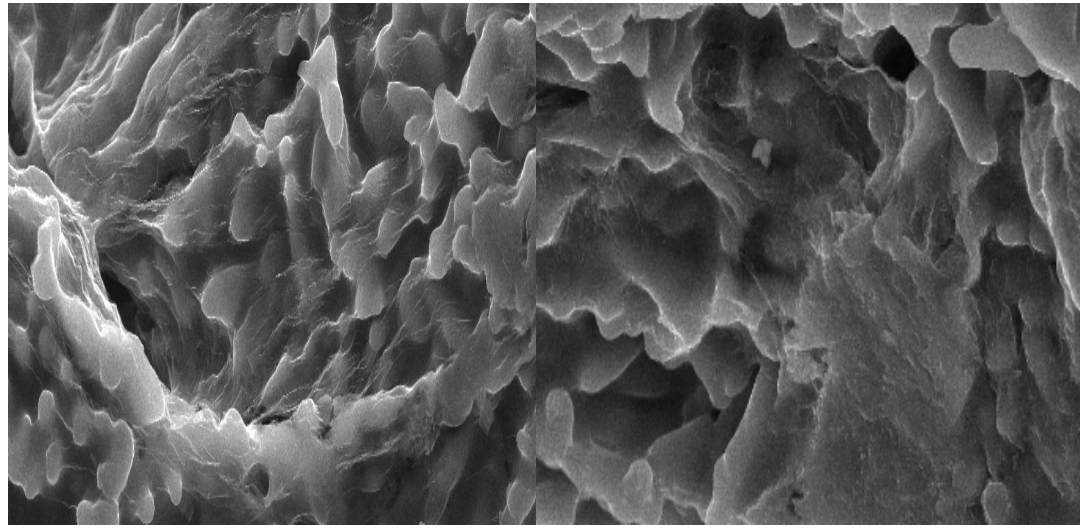

(e)

(f)

Figure 3: Surface morphologies of AlSipowderwith MWCNT a)- AlSiwith 0wt\%MWCNT b) -AlSiwith $0.25 w t \% M W C N T$ c)- AlSiwith 0.50wt\%MWCNT d)- AlSiwith $0.75 w t \%$ MWCNTe) and f) images predict the CNTsspread over the surface of AlSi.

Figure.3 shows dispersion morphologies of MWCNTS in AlSi. (Fig.3a) depictsAlSipowderwithoutMWCNTssuggests the irregularshape of powder; thereis an effect of ballmilling. In the AlSiMWCNT powder mixtures (Fig.3c-d), MWCNTsdistributed over the surface of AlSiwith no greater change in shape and no-cold welding of powders(Pérez-Bustamante et al., 2012). There willbeconsideredsevere plastic deformationoccurs to Aluminium powder and MWCNTsduringhighenergyballmillingprocess(Kallip et al., 2015). (Fig.4c-d) the MWCNT content is $(0.25,0.50 \& 0.75) \mathrm{wt} \%$ isless to avoidagglomerationeffect(Choi et al., 2013). But in (Figure.3e-f) thereis a formation of the MWCNT cluster in the powders of $0.5 \& 0.75 \mathrm{wt} \%$ MWCNT(Suárez et al., 2014). 


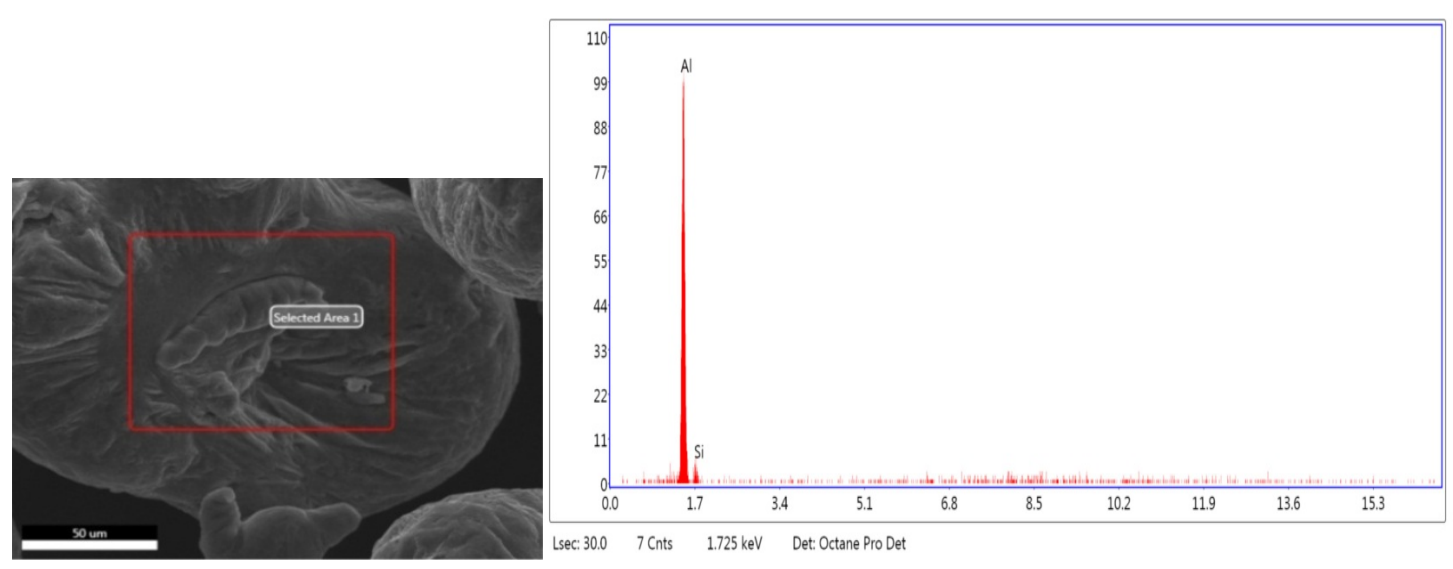

\begin{tabular}{|c|c|c|}
\hline Element & Weight \% & Atomic \% \\
\hline $\mathrm{AlK}$ & 86.32 & 86.79 \\
\hline $\mathrm{SiK}$ & 13.68 & 13.21 \\
\hline
\end{tabular}
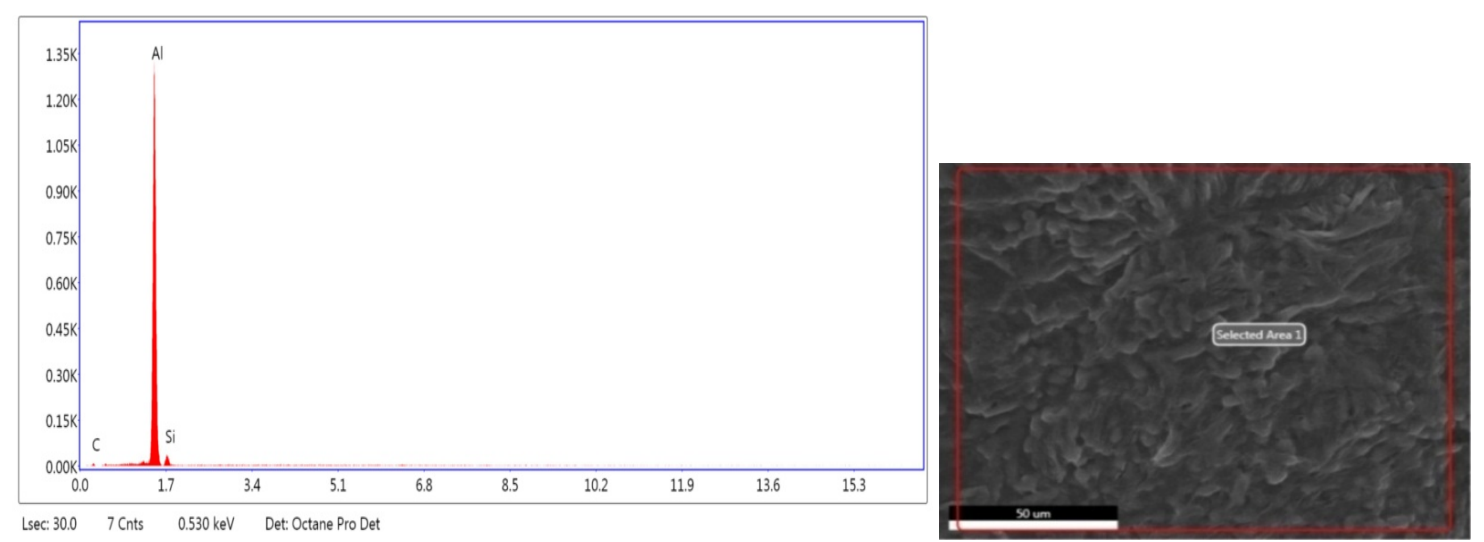

\begin{tabular}{|c|c|c|}
\hline Element & Weight \% & Atomic \% \\
\hline $\mathrm{C} \mathrm{K}$ & 2.90 & 6.31 \\
\hline $\mathrm{AlK}$ & 88.03 & 85.25 \\
\hline $\mathrm{SiK}$ & 9.07 & 8.43 \\
\hline
\end{tabular}

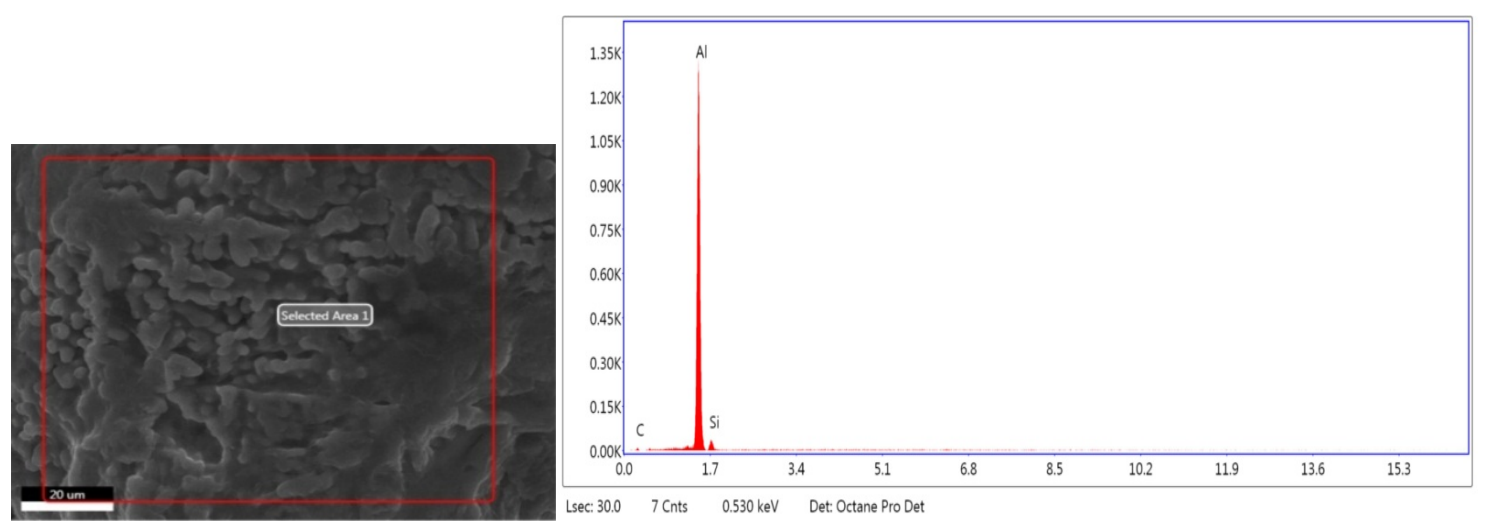




\begin{tabular}{|c|c|c|}
\hline Element & Weight \% & Atomic \% \\
\hline $\mathrm{C} \mathrm{K}$ & 14.24 & 27.23 \\
\hline $\mathrm{AlK}$ & 78.86 & 67.13 \\
\hline $\mathrm{SiK}$ & 6.90 & 5.64 \\
\hline
\end{tabular}
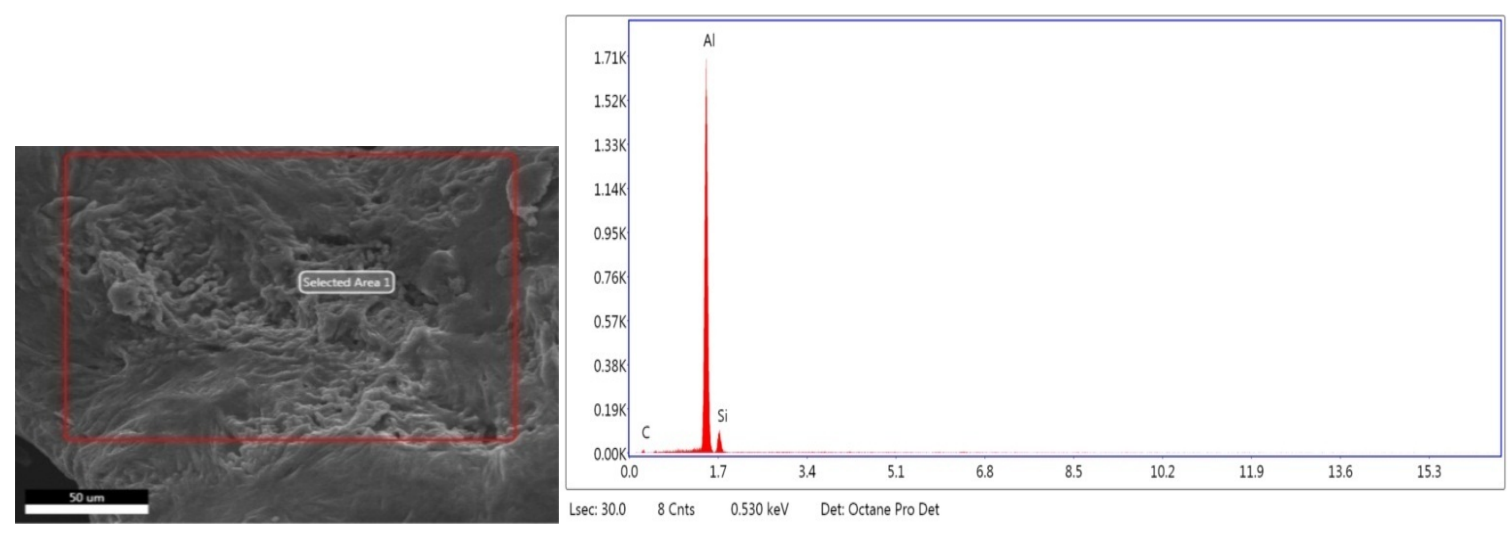

\begin{tabular}{|c|c|c|}
\hline Element & Weight \% & Atomic \% \\
\hline $\mathrm{C} \mathrm{K}$ & 15.99 & 30.07 \\
\hline $\mathrm{AlK}$ & 71.75 & 60.07 \\
\hline $\mathrm{SiK}$ & 12.27 & 9.86 \\
\hline
\end{tabular}

Figure 4: EDX of samples a) AlSi; b) AlSi+0.25wt\% MWCNT;c) AlSi+0.50wt\% MWCNT; AlSi+0.75wt\% MWCNT

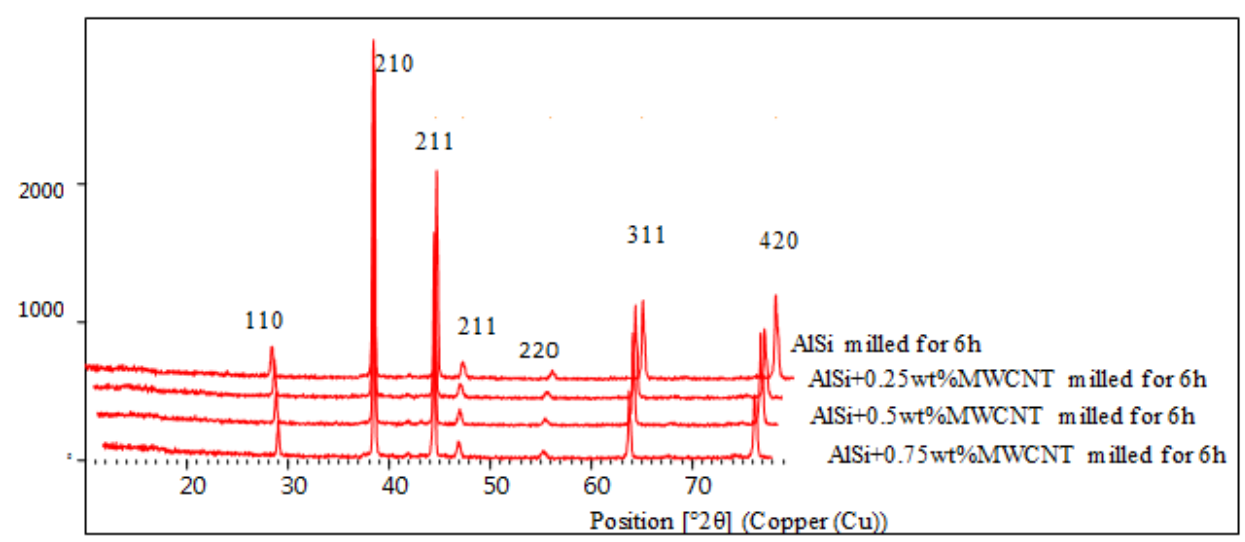

Figure 5: XRD Patterns of AlSi-MWCNT Powders

Table 1:Density of FGM atDifferentWeight Fraction of CNT

\begin{tabular}{|c|c|c|c|}
\hline $\begin{array}{c}\text { MWCNT } \\
\text { wt \% }\end{array}$ & $\begin{array}{c}\text { Theoreticaldensity } \\
\left(\mathbf{g} / \mathbf{c m}^{\mathbf{3}}\right)\end{array}$ & $\begin{array}{c}\text { Measureddensity } \\
\left(\mathbf{g} / \mathbf{c m}^{\mathbf{3}}\right)\end{array}$ & $\begin{array}{c}\text { Relative } \\
\text { density }\end{array}$ \\
\hline 0 & 2.7 & 2.537 & 93.9 \\
\hline 0.25 & 2.690 & 2.457 & 91.3 \\
\hline 0.5 & 2.675 & 2.426 & 90.69 \\
\hline 0.75 & 2.666 & 2.417 & 90.66 \\
\hline
\end{tabular}


Table 2:Hardness vs. AlSiwith MWCNT controlled variation over the length of the specimen.

\begin{tabular}{|l|c|}
\hline MWCNT wt\% & Micro-Hardness (HV) \\
\hline AlSi & 67 \\
\hline AlSi+0.25wt\%mwcnt & 72 \\
\hline AlSi+0.50wt\%mwcnt & 78 \\
\hline AlSi+0.75wt\%mwcnt & 85 \\
\hline
\end{tabular}

\section{CONCLUSIONS}

- Functionallygradedmaterial composite successfullyproduced by powdermetallurgywith extrusion technique by controlled variation of the MWCNT constituent over the AlSi matrix from $0 \mathrm{wt} \%$ to $0.75 \mathrm{wt} \%$.

- It is an major breakthrough in the field of material science becauseitis the first of itskind in FGM by Powder metallurgywith respect to the length.

- The microstructural evaluationdid use SEM to validate the uniform distribution of MWCNTs on the surface of AlSiwith minimal formation of the MWCNT cluster, EDX graph confirming the presence of AlSi and MWCNT weight and atomic\%.

- Optical microscopic images are predictinguniformcontrolled variation of one constituent over the other.

- Hardness value increasedfrom $67 \mathrm{HV}$ to $85 \mathrm{HV}$ with an increment of $78 \%$ in a linear direction; the relative density of the composite decreased. XRD peaksevaluate the presence of bothAlSi and MWCNT.

\section{REFERENCES}

1. Al-Aqeeli, N. (2013). Processing of CNTs reinforced al-based nanocomposites using different consolidation techniques. Journal of Nanomaterials, 2013, 14-20. https://doi.org/10.1155/2013/370785

2. Chen, B., Kondoh, K., Imai, H., Umeda, J., \& Takahashi, M. (2016). Simultaneously enhancing strength and ductility of carbon nanotube/aluminum composites by improving bonding conditions. Scripta Materialia, 113, 158-162. https://doi.org/10.1016/j.scriptamat.2015.11.011

3. Chen, Z., Li, W., Negahban, M., Saiter, J. M., Delpouve, N., Tan, L., \& Li, Z. (2018). Approaching the upper bound of load capacity: Functional grading with interpenetrating polymer networks. Materials and Design, 137, $152-163$. https://doi.org/10.1016/j.matdes.2017.10.019

4. Choi, H., Wang, L., Cheon, D., \& Lee, W. (2013). Preparation by mechanical alloying of Al powders with single-, double-, and multi-walled carbon nanotubes for carbon/metal nanocomposites. Composites Science and Technology, 74, 91-98. https://doi.org/10.1016/j.compscitech.2012.10.011

5. Kallip, K., Leparoux, M., Alogab, K. A., Clerc, S., Deguilhem, G., Arroyo, Y., \& Kwon, H. (2015). Investigation of different carbon nanotube reinforcements for fabricating bulk AlMg5 matrix nanocomposites. Journal of Alloys and Compounds, 646, 710-718. https://doi.org/10.1016/j.jallcom.2015.06.169

6. Khorsand, M., \& Tang, Y. (2018). On the qualitative dynamics of rotating disks: Thermal shocks and structural integrity. International Journal of Pressure Vessels and Piping, 166, 35-47. https://doi.org/10.1016/j.ijpvp.2018.08.001

7. Kim, D., Park, K., Kim, K., Miyazaki, T., Joo, S., Hong, S., \& Kwon, H. (2019). Carbon nanotubes-reinforced aluminum alloy functionally graded materials fabricated by powder extrusion process. Materials Science and Engineering A, 745, 379-389. 
https://doi.org/10.1016/j.msea.2018.12.128

8. Kumanan, M., et al. "Extraction of potash from K-Feldspar mineral by acid and molten salt leaching processes." IASET Int. J. Metall. Mater. Chem. Eng 7 (2016): 1-10.

9. Kumar, T. Vijaya, et al. "Sintering of Iron Powder mixtures and determining their mechanical properties." International Journal of Mechanical and Production Engineering Research and Development 8.3 (2018): 59-66.

10. Ramaswamy, R., et al. "Investigation of densification behaviour on yttrium oxide reinforced Ti-6Al-4V nano-composite through powder metallurgy." Int J Mech Prod Eng Res Dev 8.2 (2018): 433-442.

11. Saber, D., Kh Abd El-Aziz, and A. Fathy. "Corrosion behavior of copper-alumina nanocomposites in different corrosive media." Int. J. Mech. Eng 5 (2016): 1-10.

12. Lin, C. Y., McShane, H. B., \& Rawlings, R. D. (1996). Extrusion process for manufacture of bulk functionally graded materials. Powder Metallurgy, 39(3), 219-222. https://doi.org/10.1179/pom.1996.39.3.219

13. Liu, S., Wang, X., Pan, Q., Li, M., Ye, J., Li, K., Peng, Z., \& Sun, Y. (2020). Investigation of microstructure evolution and quench sensitivity of $\mathrm{Al}-\mathrm{Mg}-\mathrm{Si}-\mathrm{Mn}-\mathrm{Cr}$ alloy during isothermal treatment. Journal of Alloys and Compounds, 826. https://doi.org/10.1016/j.jallcom.2020.154144

14. Liu, Z. Y., Xu, S. J., Xiao, B. L., Xue, P., Wang, W. G., \& Ma, Z. Y. (2012). Effect of ball-milling time on mechanical properties of carbon nanotubes reinforced aluminum matrix composites. Composites Part A: Applied Science and Manufacturing, 43(12), 2161-2168. https://doi.org/10.1016/j.compositesa.2012.07.026

15. Luo, Y. H., Huang, Z. W., \& Zhang, X. L. (2007). FEM analysis of external inversion and energy absorbing characteristics of inverted tubes. Journal of Materials Processing Technology, 187-188, 279-282. https://doi.org/10.1016/j.jmatprotec.2006.11.125

16. Mahamood, R. M., Akinlabi, E. T., Shukla, M., \& Pityana, S. (2012). Functionally graded material: An overview. Lecture Notes in Engineering and Computer Science, 3, 1593-1597.

17. Maruyama, T., Kondo, H., Ghosh, R., Kozawa, A., Naritsuka, S., Iizumi, Y., Okazaki, T., \& Iijima, S. (2016). Single-walled carbon nanotube synthesis using Pt catalysts under low ethanol pressure via cold-wall chemical vapor deposition in high vacuum. Carbon, 96, 6-13. https://doi.org/10.1016/j.carbon.2015.09.010

18. Pérez-Bustamante, R., Bueno-Escobedo, J. L., Jiménez-Lobato, J., Estrada-Guel, I., Miki-Yoshida, M., Licea-Jiménez, L., \& Martínez-Sánchez, R. (2012). Wear behavior in Al2024-CNTs composites synthesized by mechanical alloying. Wear, 292-293, 169-175. https://doi.org/10.1016/j.wear.2012.05.016

19. Powell, A. (2013). The Fabrication of Aluminium-Carbon Nanotube Metal Matrix Composites. July.

20. Rao SS, U. G. (2015). Fabrication of Functionally Graded Carbon Nanotube-Reinforced Aluminium Matrix Laminate by Mechanical Powder Metallurgy Technique - Part I. Journal of Material Science \& Engineering, 04(03). https://doi.org/10.4172/2169-0022.1000169

21. Salesky, W. H. (1987). New Method for Synthesizing a Six Hour Unit Hydrograph.79, 738-743.

22. shankar, R. S., waran, S. M., \& haran, E. H. (2016). Characterization of Mechanical Properties and Wear behaviour of Aluminium-Silicon Piston Alloy. International Journal of Mechanical Engineering, 3(1), 1-3. https://doi.org/10.14445/23488360/ijme-v3i1p101

23. Sobczak, J. J., \& Drenchev, L. (2013). Metallic Functionally Graded Materials: A Specific Class of Advanced Composites. Journal of Materials Science and Technology, 29(4), 297-316. https://doi.org/10.1016/j.jmst.2013.02.006 
24. Suárez, S., Ramos-Moore, E., Lechthaler, B., \& Mücklich, F. (2014). Grain growth analysis of multiwalled carbon nanotubereinforced bulk Ni composites. Carbon, 70(681), 173-178. https://doi.org/10.1016/j.carbon.2013.12.089

25. Tang, Y., Qiu, W., Chen, L., Yang, X., Song, Y., \& Tang, J. (2020). Preparation of W-V functionally gradient material by spark plasma sintering. Nuclear Engineering and Technology. https://doi.org/10.1016/j.net.2020.01.008

26. Topolski, K., Wieciński, P., Szulc, Z., Gatka, A., \& Garbacz, H. (2014). Progress in the characterization of explosively joined Ti/Ni bimetals. Materials and Design, 63, 479-487. https://doi.org/10.1016/j.matdes.2014.06.046

27. Watari, F., Yokoyama, A., Saso, F., Uo, M., \& Kawasaki, T. (1997). Fabrication and properties of functionally graded dental implant. Composites Part B: Engineering, 28(1-2), 5-11. https://doi.org/10.1016/s1359-8368(96)00021-2 